\title{
SEISMIC PROBABILISTIC RISK ASSESSMENT OF NUCLEAR POWER PLANTS USING RESPONSE-BASED FRAGILITY CURVES
}

\author{
Ying-Hsiu Shen ${ }^{1}$, Chang-Ching Chang ${ }^{1}$, and Yin-Nan Huang ${ }^{2}$ \\ ${ }^{1}$ National Center for Research on Earthquake Engineering, Taiwan (yhshen@ncree.narl.org.tw) \\ ${ }^{2}$ Assistant Professor, Department of Civil Engineering, National Taiwan University, Taiwan
}

\begin{abstract}
Seismic probabilistic risk assessment (SPRA) has been widely used to compute the frequencies of core damage and release of radiation of a nuclear power plant (NPP). In 2011, Huang et al. published a SPRA methodology with the following characteristics different from the widely used Zion method: (a) seismic fragility curves are defined as a function of structural response parameters, such as floor spectral acceleration and story drift; (b) nonlinear response-history analysis is used to estimate statistical distributions of seismic demands for structural and non-structural components of NPPs; (c) Monte Carlo simulation is used to determine damage states of structural and non-structural components. In the study presented in this paper, the seismic risk of a sample NPP was evaluated using the methodology of Huang et al. The seismic risk was defined as the mean annual frequency of core damage (CDF) contributed by 2 sample accident sequences. Conditional mean spectra were used as the target spectra for ground-motion scaling. The study shows that the sample accident sequences have a CDF of $6.5 \times 10^{-6}$ per year.
\end{abstract}

\section{INTRODUCTION}

The United States Nuclear Regulatory Commission (USNRC) issued Supplement 4 to Generic Letter No. 88-20 (USNRC 1991) in 1991 requiring nuclear power plant utilities to perform an Individual Plant Examination of External Events (IPEEE) and also issued NUREG-1407 (Chen et al. 1991) to help guide the IPEEE. For an Individual Plant Examination (IPE) of seismic events, NUREG-1407 identified Seismic Probabilistic Risk Assessment (SPRA) as an acceptable methodology for the examination of earthquake-induced risks. SPRA provides a formal process in which the randomness and uncertainty in seismic input, structure response and material capacity is considered in the computation of risk. NUREG/CR-2300 (USNRC 1983) provides general guidance for performing SPRA for NPPs. The guideline describes two SPRA methods: (1) Zion and (2) the Seismic Safety Margin (SSM). The Zion method was first developed and applied in the Oyster Creek probabilistic risk assessment and later improved and applied in 1981 to estimate seismic risk for the Zion Plant (Pickard et al. 1981). The SSM method was developed in an NRC-funded project termed "the Seismic Safety Margin Research Program (SSMRP)" at the Lawrence Livermore National Laboratory (Smith et al. 1981).

Recently, Huang et al. (2011a, 2011b) proposed a SPRA methodology, which is based on the conventional methods described above and the new tools developed for the next-generation performancebased earthquake engineering (ATC 2012, Der Kiureghian 2005, Yang 2009). The method of Huang et al. differs in many regards from methods used to date for the probabilistic risk assessment of NPPs. Key differences include 1) the use of component fragility curves that are expressed in terms of structural responses (e.g., story drift and peak floor acceleration) and not on ground-motion intensity (e.g., peak ground acceleration), 2) the characterization of earthquake shaking using seismic hazard curves, and 3) procedures for both scaling earthquake ground motions and assessment of component damage.

In the study presented in this paper, the seismic risk of a sample NPP was evaluated using the methodology of Huang et al. The seismic risk was defined as the mean annual frequency of core damage 
(CDF) contributed by 2 sample accident sequences. The development of structural-response-based fragility curves for this study is presented in a companion paper, Chang et al. (2013). The following sections present the methodology of Huang et al. and each step of the seismic risk computation for the sample NPP.

\section{SPRA METHODOLOGY OF HUANG ET AL.}

The SPRA methodology of Huang et al. (2011a, 2011b) includes five steps, as presented in Figure 1. Step 1 of the methodology performs plant system analysis of a NPP to establish the accident sequences that could result in target unacceptable performance, such as core damage and large early release of radiation. The event trees and fault trees associated with the identified accident sequences are developed. The fragility curves for structural and non-structural components included in the identified accident sequences are developed in terms of structural response parameters. Step 2 develops the mean seismic hazard curve for the NPP site and divides the curve into 8 equal intervals. Acceleration histories of ground motions are selected and scaled for each intensity level. Step 3 performs nonlinear responsehistory analysis at each intensity level and identifies the distributions and correlation of all structural response parameters used to express the fragility curves of Step 1. Step 4 uses Monte Carlo method to generate a significant number of response data that are statistically consistent with those of Step 3 and to identify the possible distribution of damage to structural and non-structural components of the NPP at each intensity level. Step 5 computes the probability of target unacceptable performance at each intensity level using event trees and fault trees of Step 1 and calculates the annual frequency of target unacceptable performance of the NPP.

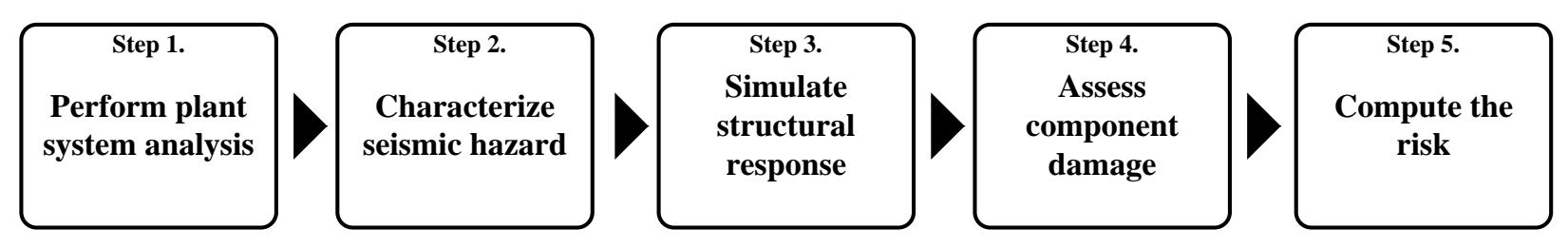

Figure 1. The procedures for the SPRA methodology of Huang et al. (2011a, 2011b).

\section{THE SAMPLE NUCLEAR POWER PLANT}

The sample nuclear power plant hosts boiling water reactors. Three buildings of the sample nuclear power plant were included in this study, namely, a reactor building (RB), a control building (CB) and an auxiliary fuel building (AFB). The lumped mass-beam 3D models were developed for the buildings using the computer code SAP2000 (CSI, 2006). The first mode periods in the two horizontal and the vertical directions are $0.197 \mathrm{~s}, 0.214 \mathrm{~s}$ and $0.094 \mathrm{~s}$, respectively, for the RB; $0.104 \mathrm{~s}, 0.098 \mathrm{~s}$ and $0.039 \mathrm{~s}$ for the CB; and $0.128 \mathrm{~s}, 0.105 \mathrm{~s}$ and $0.040 \mathrm{~s}$ for the AFB. Total weights of the sample RB, CB and AFB are 206,830, 48,870 and 59,416 tons, respectively. Only the model for the RB is discussed herein.

Figure 2 presents the lumped mass-beam 3D models for the RB subjected to horizontal shaking (panel a) and vertical shaking (panel b). In each panel, the model is composed of four sticks representing the external containment structure $(\mathrm{R} / \mathrm{B})$, the reinforced concrete containment vessel (RCCV), the reactor shield wall (RSW) and the reactor pressure vessel (RPV), respectively. The beam elements in each stick consider shear, bending and axial deformations. Masses are basically lumped at upper surface levels of floor slabs and include rotational inertia. Except for the soil springs, the vertical springs in panel $b$ of Figure 2 account for slab flexibility. Dynamic properties for frequency-independent soil springs (namely, spring and damping coefficient) were developed in time domain using SHAKE equivalent linearization analysis. The sticks for $\mathrm{R} / \mathrm{B}$ and $\mathrm{RCCV}$ are connected by rigid links in the model of Figure 2(a) to consider rigid in-plane slab stiffness. 


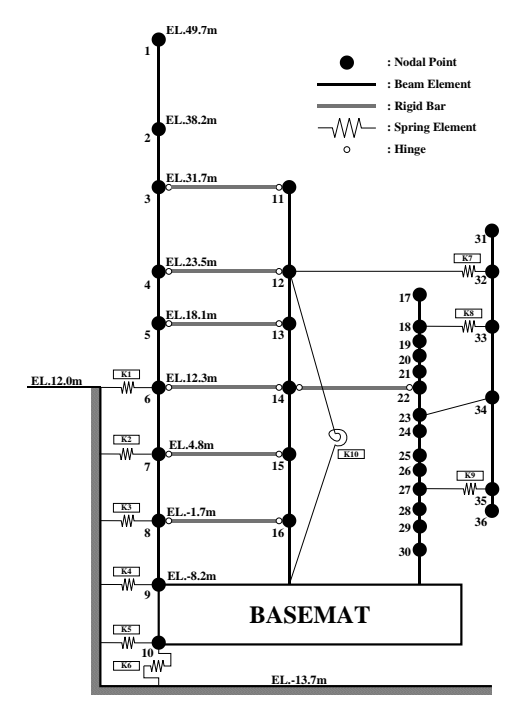

(a) RB model for horizontal shaking

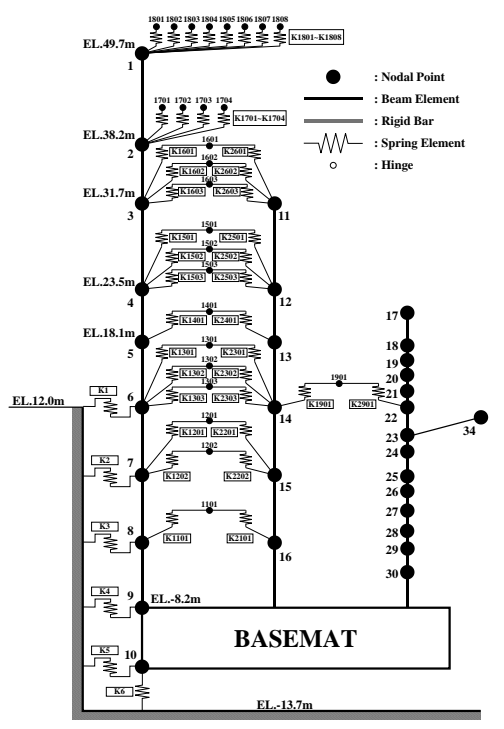

(b) RB model for vertical shaking

Figure 2. Lumped-mass-beam models for the sample reactor building.

\section{STEP 1: PLANT SYSTEM ANALYSIS AND FRAGILITY CURVES}

Figure 3 presents the seismic event trees for the core damage event of the sample NPP. The seismic risk assessments performed in this study focus on the core damage frequency caused by two specific accident sequences, which are numbered \#2 and \#12 in Figure 3. Sequences \#2 and \#12 both start from a seismic event (SE), end at core damage and consist a series of safety functions (SFs) in between. The related SFs include the off-site power (LOP), the structural integrity (SI), the emergency DC power (EDC), the emergency AC buses (EAC), the service water (SW) system, the emergency diesel generators (EDG), the swing diesel generator (SDG), the reactivity control (C), the SRVs open and reclose (PO and PC), reactor core isolation cooling (RCIC) coolant injection (UR1), RPV depressurization (X) and the AC independent water addition system (ACIWA).

All branches in Figure 3, except that for the initiating event SE, appear in pairs. The upper branches represent success of the SFs and the lower branches represent failure. The failures of the related SFs in sequence \#2 are LOP, EDG, SDG and ACIWA systems but the failures of the related SFs in sequence \#12 are LOP, SW, EDG and ACIWA systems. For example, the accident sequence \#12 is triggered by a seismic event, which results in a loss of off-site power. Although all the safety-related structures maintain their integrity during the earthquake, the service water system fails, which results in the failure of emergency diesel generator. Swing diesel generator has its own service water system and survives in this accident sequence. Scram succeeds representing that the process of safety control rod insertion is finished. Under these conditions, RCIC provides core cooling for about 8 hours as designed. Subsequently, the reactor is depressurized to permit the ACIWA inject water into the reactor. However, the ACIWA fails which results in core damage.

A fault tree identifies the various combinations and sequences of the failure of NPP components leading to the failure of a given SF. Figure 4 presents the fault tree for the ACIWA system in the sample NPP. The structural and non-structural components at the lowest level of a fault tree are termed "basic" components in this paper. The probability of the successful SFs (e.g. SI, EDC, EAC, etc) involved in sequence \#2 and \#12 is assumed as unity. The other SFs which fail to operate in sequence \#2 and \#12 involve with 43 basic components at the lowest level of their fault trees. Response-based fragility curves 
were developed for these basic components. Fragility curves used in this study are the cumulative distribution functions of logarithmic normal distributions, as presented in the following equation:

$$
G_{C}(a)=\Phi\left[\frac{\ln (a / \hat{a})}{\beta_{C}}\right]
$$

where $G_{C}(a)$ is the probability of failure of a NPP component at a given value $a$ of a structural response parameter critical for the functionality of the component and $\hat{a}$ is the median capacity of the component. Parameter $\beta_{C}$ is the composite logarithmic standard deviation in the capacity of the component, including both aleatory variability and epistemic uncertainty. In this study, 23 response parameters were identified for the 43 basic components since the fragility curves for different components may be expressed using the same response parameter. Figure 5 presents the fragility curve used in this study for reactor heat removal (RHR) piping, one of the basic component for ACIWA. The fragility curve was developed as a function of the peak $2 \%$-damped vertical floor spectral acceleration (VFSA) at frequencies between 7 and $15 \mathrm{~Hz}$ at Node 16 of the model of Figure $2 \mathrm{~b}$ and has a median value of 6.7 and $\beta_{C}$ of 0.39 . See Chang et al. (2013) for more information regarding the development of structural-response-based fragility curves used in this study.

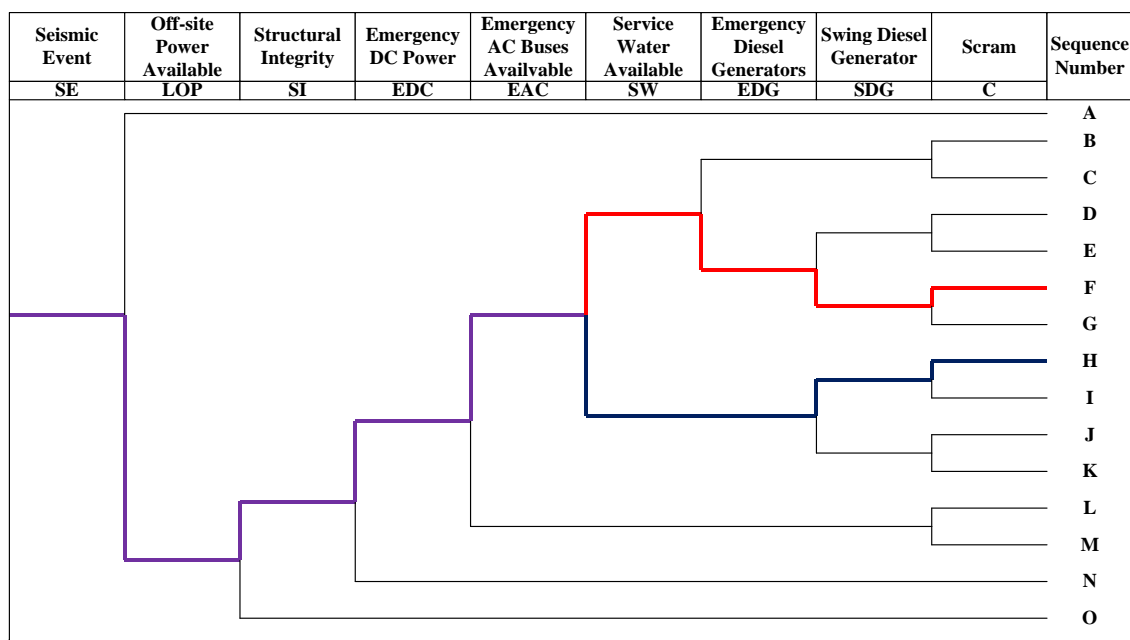

(a) Main seismic event tree of the sample NPP

\begin{tabular}{|c|c|c|c|c|c|c|}
\hline $\begin{array}{c}\text { Seismic } \\
\text { Station } \\
\text { Blackout }\end{array}$ & SRVs Open & SRVs Reclose & $\begin{array}{c}\text { Coolant } \\
\text { Injection By } \\
\text { RCIC }\end{array}$ & $\begin{array}{c}\text { RPV } \\
\text { Depress- } \\
\text {-urization }\end{array}$ & $\begin{array}{c}\text { AC independent } \\
\text { Water Addition }\end{array}$ & $\begin{array}{c}\text { Sequence } \\
\text { Number }\end{array}$ \\
\hline F & PO & PC & UR1 & X & ACIWA & \\
\hline
\end{tabular}

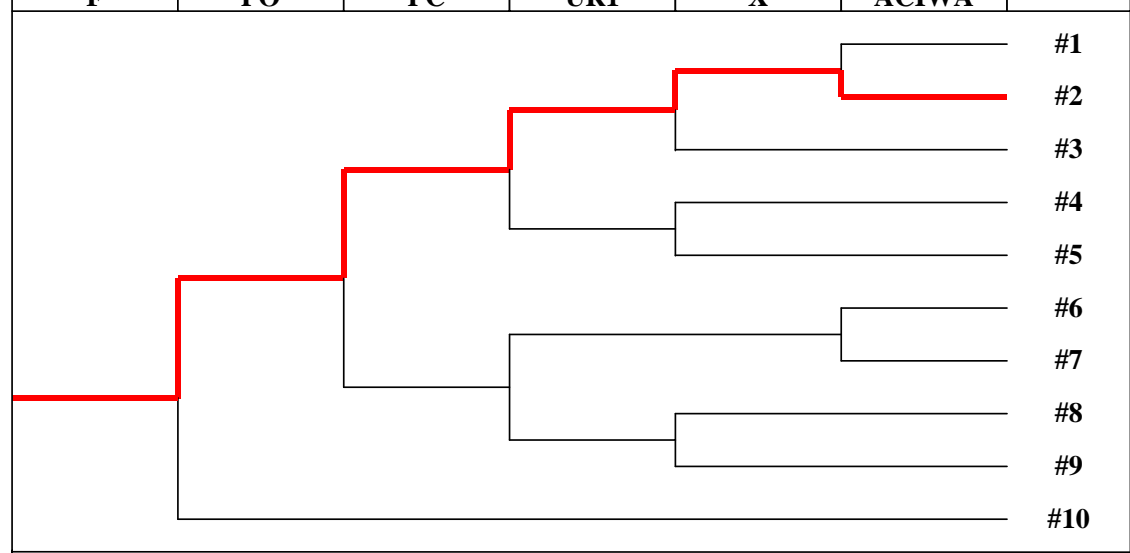

(b) Seismic event tree following Accident Sequence F of Panel (a) 


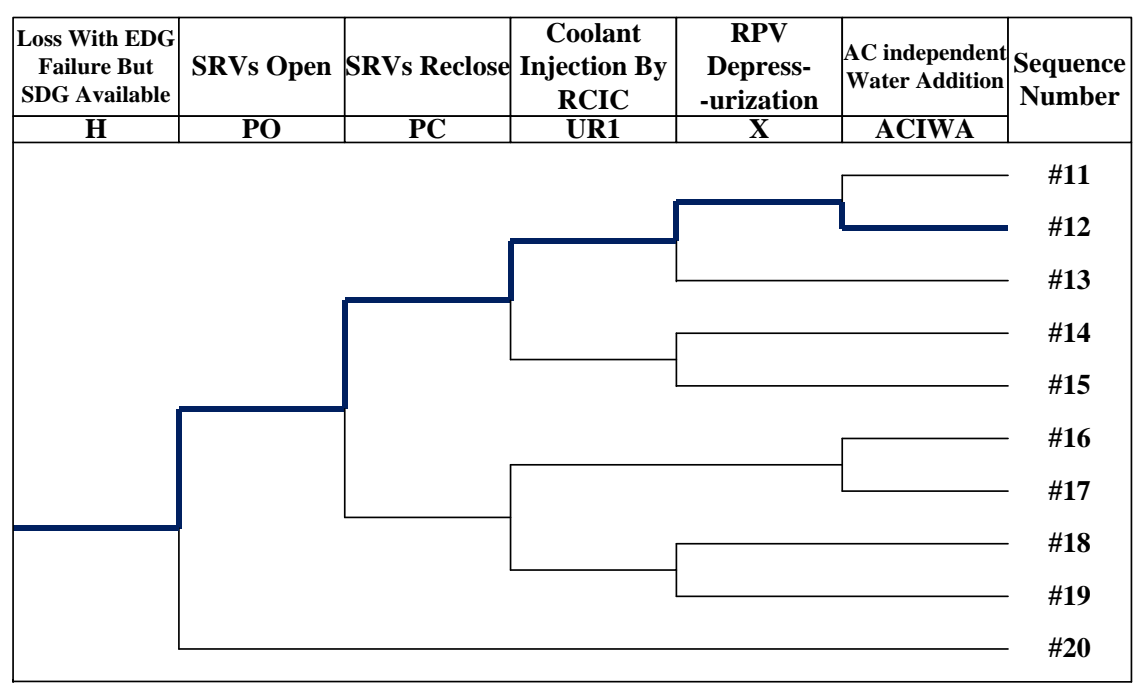

(c) Seismic event tree following Accident Sequence H of Panel (a)

Figure 3. Seismic event trees of the sample NPP.

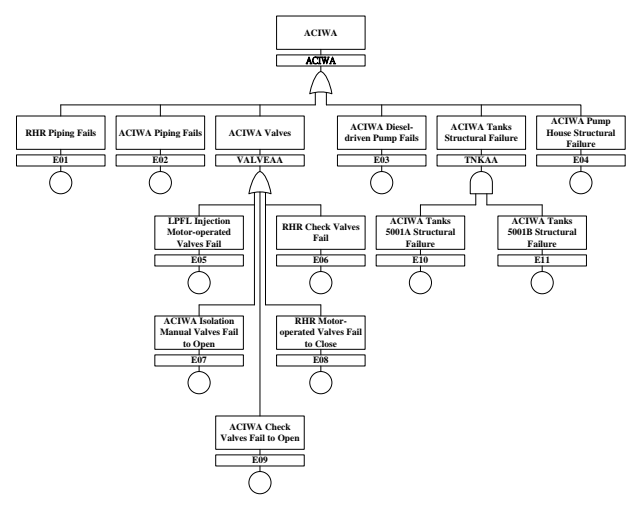

Figure 4. Fault tree for ACIWA system in the sample NPP.

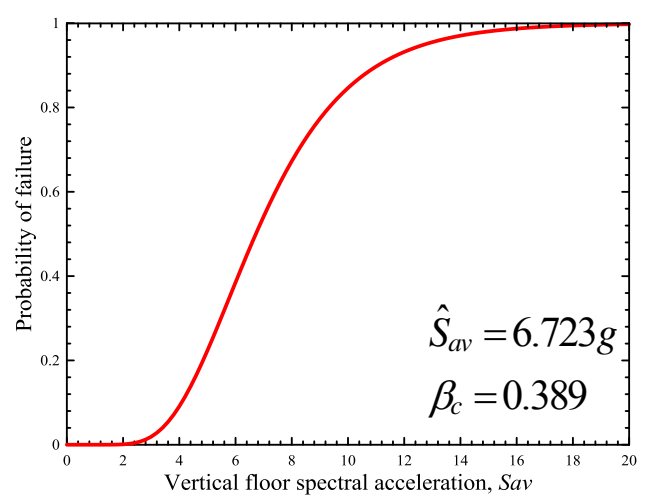

Figure 5. Fragility curve for RHR piping.

\section{STEP 2: SEISMIC HAZARD}

The sample NPP is assumed sited close to Taipei, Taiwan. Seismic hazard for the sample NPP site, as presented in Figure 6, was developed as a function of spectral acceleration $\left(S_{a}\right)$ at the fundamental period of the reactor building, which is 0.2 second in this case. The range of spectral acceleration in the hazard curve of Figure 6 is between 0 to $3.2 \mathrm{~g}$, where $3.2 \mathrm{~g}$ is associated with a mean annual frequency of exceedance (MAFE) of $7.98 \times 10^{-7}$. The range of spectral acceleration was split into 8 equal intervals (termed $\Delta e_{i}, i=1-8$ in Figure 6) representing 8 ground-motion intensity levels. The midpoint values of the 8 intervals (termed $S_{a, i}, i=1-8$ ) range from $0.2 \mathrm{~g}$ to $3.0 \mathrm{~g}$ with increments of 0.4 g. Each intensity level of the seismic hazard is associated with a mean annual frequency of occurrence, termed $\Delta \lambda_{H, i}$ in Figure 6 . The fourth column of Table 1 presents the value of $\Delta \lambda_{H, i}$ for each groundmotion intensity level.

For each $S_{a, i}$, the modal magnitude-distance pair was identified using the de-aggregation data for the sample NPP site and a conditional mean spectrum (CMS. Baker and Cornell 2006) anchored to the given $S_{a, i}$ was developed and used as the target spectrum for scaling of ground motions for responsehistory analysis of the sample NPP. The red dots of Figure 7 present the values of CMS for $S_{a, 3}$. The 
CMS of Figure 7 was developed using the attenuation relationship of Campbell and Bozorgnia (2008) with a moment magnitude of 6.9 , a closest site-to-source distance of $17.8 \mathrm{~km}$, and an average shear wave velocity of $1,200 \mathrm{~m} / \mathrm{s}$ based on the de-aggregation data and site condition for the sample NPP site. In this study, twenty sets of ground motions from PEER ground-motion database were selected and scaled for each intensity level. Each set of ground motions includes two horizontal components and one vertical component. The three components of a given ground-motion set were scaled by a single factor determined using the greedy optimization procedure of Jayaram et al. (2011). Both the median and dispersion in the spectral ordinates of the selected ground motions were considered in the optimization process. The thin lines of Figure 7 present the geometric-mean spectra of the horizontal components of the 20 scaled ground motions selected for $S_{a, 3}$ and the thick line presents the median of the 20. As shown in the figure, the median spectral accelerations of Figure 7 agree well with their target values (i.e., the CMS). The process was repeated for all the other intensity levels. The scaled ground motions are used in the response-history analysis for the sample NPP.

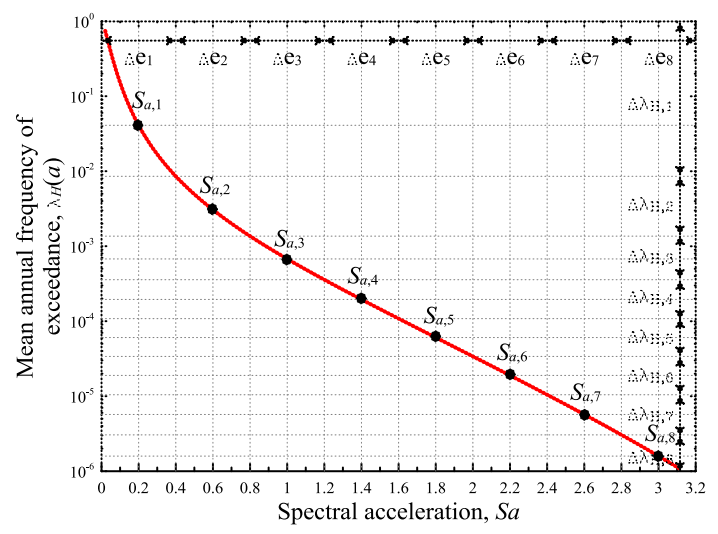

Figure 6. Seismic hazard curve for the site of the sample NPP.

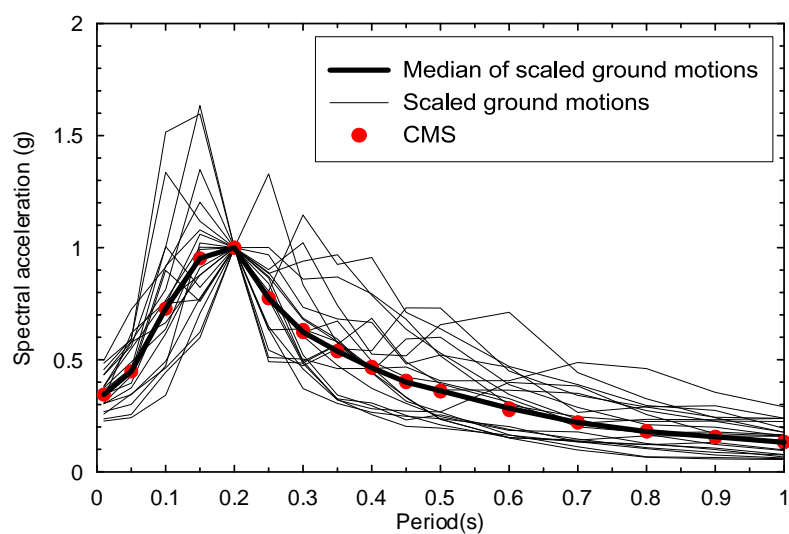

Figure 7. The conditional mean spectrum and acceleration spectra of the 20 scaled ground motions for $S_{a, 3}$.

Table 1. Seismic risk of the sample NPP for Accident Sequences \#2 and \#12 of Figure 3 at each groundmotion intensity level.

\begin{tabular}{|c|c|c|c|c|}
\hline \multicolumn{2}{|c|}{$\begin{array}{c}\text { Ground-motion } \\
\text { intensity level } \\
\left(S_{a, i}\right)\end{array}$} & $\begin{array}{c}\text { Probability of core } \\
\text { damage, } P_{U P}\left(S_{a, i}\right)\end{array}$ & $\begin{array}{c}\text { Mean annual frequency of } \\
\text { occurrence, } \Delta \lambda_{H, i}\end{array}$ & $\begin{array}{c}\text { Annual frequency of core } \\
\text { damage, } P_{U P}\left(S_{a, i}\right) \times \Delta \lambda_{H, i}\end{array}$ \\
\hline$S_{a, 1}$ & $0.2 \mathrm{~g}$ & 0.000 & $9.914 \times 10^{-1}$ & 0.000 \\
\hline$S_{a, 2}$ & $0.6 \mathrm{~g}$ & $2.000 \times 10^{-5}$ & $7.198 \times 10^{-2}$ & $1.440 \times 10^{-7}$ \\
\hline$S_{a, 3}$ & $1.0 \mathrm{~g}$ & $7.200 \times 10^{-4}$ & $1.004 \times 10^{-3}$ & $7.231 \times 10^{-7}$ \\
\hline$S_{a, 4}$ & $1.4 \mathrm{~g}$ & $5.420 \times 10^{-3}$ & $2.489 \times 10^{-4}$ & $1.349 \times 10^{-6}$ \\
\hline$S_{a, 5}$ & $1.8 \mathrm{~g}$ & $2.098 \times 10^{-2}$ & $7.431 \times 10^{-5}$ & $1.559 \times 10^{-6}$ \\
\hline$S_{a, 6}$ & $2.2 \mathrm{~g}$ & $5.112 \times 10^{-2}$ & $2.346 \times 10^{-5}$ & $1.199 \times 10^{-6}$ \\
\hline$S_{a, 7}$ & $2.6 \mathrm{~g}$ & $1.243 \times 10^{-1}$ & $7.401 \times 10^{-6}$ & $9.203 \times 10^{-7}$ \\
\hline$S_{a, 8}$ & $3.0 \mathrm{~g}$ & $2.746 \times 10^{-1}$ & $2.253 \times 10^{-6}$ & $6.187 \times 10^{-7}$ \\
\hline
\end{tabular}




\section{STEP 3: STRUCTURAL RESPONSE}

A total of 160 tri-directional response-history analyses (20 sets of ground motions for each of the 8 intensity levels of Figure 6) were conducted for the sample NPP. As described earlier, 23 structural response parameters were identified and used to develop fragility curves for the 43 basic components of this study. The values of the 23 structural response parameters were recorded in each response-history analysis and a total of 8 demand-parameter matrices were developed for the 8 intensity levels. The size of the demand-parameter matrices is $20 \times 23$, where the number of row vectors is determined by the number of ground motions for a given shaking intensity and the number of columns is determined by the number of structural response parameters.

The ATC-58 Guidelines (ATC 2012) presents a procedure, which was originally proposed in Yang et al. (2009), for generating a large number of simulations (i.e., a new demand-parameter matrix with a large number of rows) through statistical manipulation of a relatively small number of structural analyses. The mean vector and covariance matrix of the natural logarithm of the new demand-parameter matrix will be the same as those of the underlying matrix from the results of response-history analysis. The procedure of the ATC-58 Guidelines and Yang et al. (2009) was used in this study to increase the number of row vectors in the demand-parameter matrix from 20 to 50,000. Sample results are presented in Figure 8, including the distributions of responses for RHR Motor Operated Valves and RHR Piping from the underlying $20 \times 23$ matrix and the $50,000 \times 23$ matrix generated per Yang et al. at the groundmotion intensity level for $S_{a, 3}$. The values generated per the Yang et al. procedure preserve the magnitude and correlation in the responses obtained using response-history analysis.

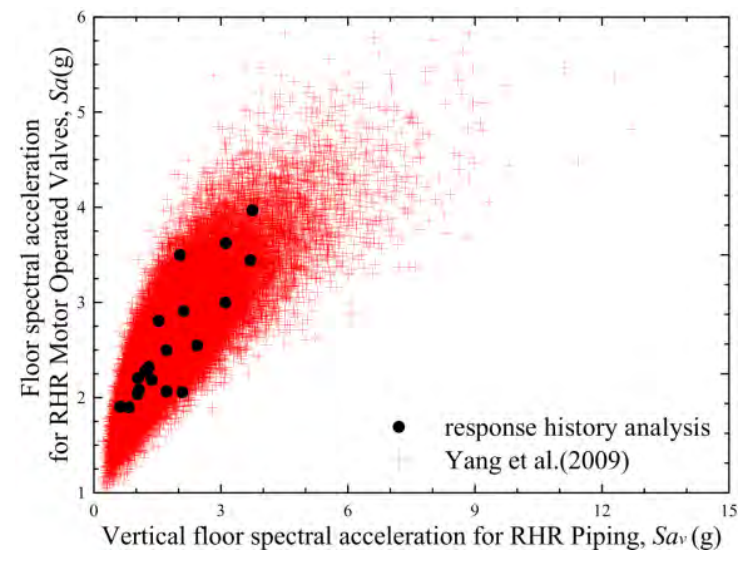

Figure 8. Distributions of a) floor spectral acceleration for RHR Motor Operated Valves and b) vertical floor spectral acceleration for RHR Piping at the ground-motion intensity level for $S_{a, 3}$ computed using response-history analysis and the procedure of Yang et al. (2009).

\section{STEP 4: DAMAGE ASSESSMENT}

Monte Carlo procedure was used to determine the damage status (i.e., success or failure) of NPP components subjected to ground shaking. For example, a response history analysis of the sample NPP identified a peak $2 \%$-damped VFSA of $3.3 \mathrm{~g}$ for the RHR piping at Node 16 in the sample reactor building. The probability of failure of the RHR piping is $3.34 \%$ at a VFSA of $3.3 \mathrm{~g}$ per the fragility curve of Figure 5. A random number generator producing random numbers uniformly distributed between 0 and 1 was used to determine the damage state for the RHR piping. If the realization generated by the random generator was smaller or equal to 0.0334 , the RHR piping was considered to have failed; and if the 
realization was greater than 0.0334 , the RHR piping was considered safe. For a given row vector in a $50,000 \times 23$ demand-parameter matrix for the sample NPP, the procedure described above was performed for all basic components to determine the damage status of each component and, based on the distribution of damage (safe or failure) in all basic components, the fault trees and event trees for the accident sequences \#2 and \#12 of Figure 3 were then used to determine whether the core was damaged or not. This procedure was repeated for each row vector in the $50,000 \times 23$ demand-parameter matrix, the probability of core damage for accident sequences \#2 and \#12 at the associated with the demand-parameter matrix can be determined by the ratio of the number of row vectors with core damage to 50,000. The third column of Table 1 presents the probabilities of core damage $\left(P_{U P}\left(S_{a, i}\right)\right)$ caused by accident sequence \#2 and \#12 for the 8 ground-motion intensity levels for the sample NPP site.

\section{STEP 5: SEISMIC RISK COMPUTATION}

The annual frequency of target unacceptable performance (i.e., core damage in this case), $\lambda_{U P}$, is the sum of the products of $P_{U P}\left(S_{a, i}\right)$ and $\Delta \lambda_{H, i}$ :

$$
\lambda_{U P}=\sum_{i=1}^{8} P_{U P}\left(S_{a, i}\right) \cdot \Delta \lambda_{H, i}
$$

The fifth column of Table 1 presents the annual frequency of core damage caused by the accident sequences \#2 and \#12 of Figure 3 for the sample NPP. Based on the results of Table 1, the annual frequency of core damage resulted from accident sequences $\# 2$ and \#12 for the sample NPP is $6.5 \times 10^{-6}$.

This study does not include the uncertainties in soil properties of the sample site and mechanical properties of the structural components of the sample NPP. On-going research is conducted by the authors of this paper to investigate the impact of these uncertainties on the seismic risk of the sample NPP.

\section{CONCLUSIONS}

The procedures and the results of a SPRA study for a sample NPP using the procedures of Huang et al. (2011a, 2011b) are presented in this paper. The procedures enable the use of response-based fragility curves and directly consider the correlation in the response of NPP components in the risk computation. The study concludes that the annual frequency of core damage contributed by two selected accident sequences of the sample NPP is $6.5 \times 10^{-6}$.

\section{REFERENCES}

Applied Technology Council (ATC). (2012). "Seismic performance assessment of buildings. Volume 1 Methodology." FEMA P-58 pre-release version, Federal Emergency Management Agency. Washington, D.C.

Baker, J. W., and Cornell, C. A. (2006). "Spectral shape, epsilon and record selection." Earthquake Engineering and Structural Dynamics, 35(9), 1077-1095.

Campbell, K. W., and Bozorgnia, Y. (2008). "NGA ground motion model for the geometric mean horizontal component of PGA, PGV, PGD and 5\% damped linear elastic response spectra for periods ranging from 0.01 to 10 s." Earthquake Spectra, 24(1), 139-171.

Chang, C.-C., Shen, Y.-H., Huang, Y.-N. and Chou, C.-C. (2013). "Development of Response-based Fragility Curves for Seismic Probabilistic Risk Assessment of Nuclear Power Plants.” Proceedings, 
22st International Conference on Structural Mechanics in Reactor Technology, San Francisco, United States.

Chen, J.T., Chokshi, N.C., Kenneally, R.M., Kelly, G.B., Beckner, W.D., McCracken, C., Murphy, A.J., Reiter, L., Jeng, D., (1991). Procedural and Submittal Guidance of Individual Plant Examination of External Events (IPEEE) for Severe Accident Vulnerabilities. NUREG-1407. U.S. Nuclear Regulatory Commission. Washington, DC.

Computers and Structures, Inc. (CSI) (2006). SAP2000 Linear and Nonlinear Static and Dynamic Analysis and Design of Three-Dimensional Structures-version 14.0. Computers and Structures, Inc., Berkeley, California.

Huang, Y.-N., Whittaker, A. S. and Luco, N. (2011a). "A Probabilistic Seismic Risk Assessment Procedure for Nuclear Power Plants: (I) Methodology," Nuclear Engineering and Design, 241(2011), 3996-4003.

Huang, Y.-N., Whittaker, A. S. and Luco, N. (2011b). "A Probabilistic Seismic Risk Assessment Procedure for Nuclear Power Plants: (II) Application," Nuclear Engineering and Design, 241(2011), 3985-3995.

Jayaram, N., Lin, T., and Baker, J. W. (2011). "A Computationally Efficient Ground-Motion Selection Algorithm for Matching a Target Response Spectrum Mean and Variance." Earthquake Spectra, 27(3), 797-815.

Kennedy, R. P. (1999). "Overview of Methods for Seismic PRA and Margin Anaylsis Including Recent Innovations," Proceedings of the OECD-NEA Workshop on Seismic Risk, Tokyo Japan.

Kiureghian, A.D. (2005). Non-ergodicity and PEER's Framework Formula. Earthquake Engineering and Structural Dynamics 34(13), 1643-1652.

Pickard, Lowe, Garrick, Inc., Westinghouse Electric Corporation, Fauske \& Associates, Inc. (1981). "Zion Probabilistic Safety Study." Prepared for Commonwealth Edison Company, Chicago.

Smith, P.D., Dong, R.G., Bernreuter, D.L., Bohn, M.P., Chuang, T.Y., Cummings, G.E., Johnson, J.J., Mensing, R.W., Wells, J.E. (1981). Seismic Safety Margins Research Program: Phase 1 Final Report. NUREG/CR-2015. U.S. Nuclear Regulatory Commission, Washington, DC.

U.S. Nuclear Regulatory Commission (USNRC) (1991). Individual Plant Examination of External Events (IPEEE) for Severe Accident Vulnerabilities. Generic Letter No. 88-20, Supplement 4. U.S. Nuclear Regulatory Commission, Washington, DC.

U.S. Nuclear Regulatory Commission (USNRC) (1983). PRA Procedures Guide. NUREG/CR-2300. U.S. Nuclear Regulatory Commission, Washington, DC.

Yang, T.Y., Moehle, J., Stojadinovic, B., Der Kiureghian, A. (2009). Performance Evaluation of Structural Systems: Theory and Implementation. Journal of Structural Engineering. 135(10), 11461154. 